\title{
The Antioxidant Phytochemicals of Nutraceutical Importance
}

\author{
Dhan Prakash* and K. R. Gupta
}

$R \& D$ Division, International Testing Centre, 86 Industrial Area, Phase-I, Panchkula-134 109 (Haryana), India

\begin{abstract}
Over production of free radicals result in oxidative stress that deregulates the cellular and metabolic functions. Phytochemicals with antioxidant property are of great interest due to their beneficial effects on human health as they offer protection against metabolic dysfunction, gastro-duodenal pathogenesis, premature aging, inflammation, rheumatoid arthritis, atherosclerosis, cancer, neuro-degenerative and cardiovascular diseases. Carotenoids, tocopherols, ascorbates, lipoic acids, polyphenols and enzymes like super oxide dismutase, catalase, glutathione peroxidase, glutathione reductase are strong natural antioxidants with free radical scavenging activity. Fruits, vegetables, cereals, legumes and beverages are the main sources of polyphenols. Flavonoids possess ideal structural characteristics, which are responsible for their pharmacological properties and are also powerful metal chelators. The future of dietary antioxidants hold a great promise to ensure a better disease free lifestyle for the mankind by scavenging free radicals and consequently preventing mutagenic changes and associated disorders.
\end{abstract}

Key Words: Free radicals, antioxidants, carotenoids, tocopherols, ascorbates, lipoic acids, polyphenols, health benefits.

\section{INTRODUCTION}

Oxygen is essential for survival and about $5 \%$ of its inhaled part is converted to reactive oxygen species (ROS) such as $\left[\mathrm{O}_{2}{ }^{-}\right]^{-}, \mathrm{H}_{2} \mathrm{O}_{2}$ and $\left[{ }^{\circ} \mathrm{OH}\right]$ by univalent reduction. They are also produced on exposure to sunlight, $\mathrm{X}$-rays, ozone, tobacco smoke, automobile exhaust, environmental pollutants and by several other physiological processes. Presence of unpaired electron in their outer orbit makes them highly reactive to damage nucleic acids, proteins, lipids and carbohydrates that consequently affect the immune functions causing degenerative diseases [1-3]. ROS are formed by fourelectron reduction of oxygen in respiratory chain followed by a partial reduction from 1 to 3 to generate super oxide anion $\left[\mathrm{O}_{2}\right]^{-}$that can be protonated at low $\mathrm{pH}$ to $\mathrm{H}_{2} \mathrm{O}_{2}$, $[\mathrm{OH}]$ and $\mathrm{H}_{2} \mathrm{O}[4,5]$. This process can be represented as:

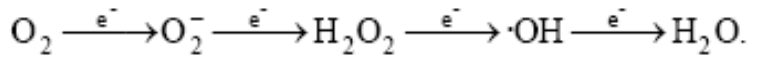

Generation of $\left[\mathrm{O}_{2}\right]^{-}$is also possible through Xanthine oxidase (EC 1.1.3.22), a molybdenum containing enzyme by activation of oxygen molecule. In addition to this, superoxides are also produced during mitochondrial respiration, by NADPH oxidase, cytochrome P-450, cyclooxygenase and lipoxygenase [6]. When production of free radicals exceeds the body's antioxidant defense system, it results in oxidative stress (OS). It is imposed on cells due to increase in oxidant generation, decrease in antioxidant protection and failure in repair of oxidative damage. Exposure to pathogens, inappropriate lifestyle, excessive exercise and byproducts of normal metabolism are also contributing factors to OS [7, 8]. OS deregulates the cellular functions leading to neurodegenerative diseases, gastro-duodenal pathogenesis, cancer,

*Address correspondence to this author at the R \& D Division, International Testing Centre, 86 Industrial Area, Phase-I, Panchkula-134 109 (Haryana), India; Email: dprakash_in@yahoo.com cataracts, premature aging, inflammation, cardiovascular and metabolic dysfunction $[1,9]$.

Antioxidants are known to defuse free radicals leading to limited risk of OS and associated disorders. At cellular and molecular levels they inactivate ROS and under specific low concentration inhibit or delay oxidative processes by interrupting the radical chain reaction of lipid peroxidation [10, 11]. Phytochemicals with antioxidant capacity naturally present in food are of great interest due to their beneficial effects on human health as they offer protection against oxidative deterioration [12]. Epidemiological and animal studies suggest that the regular consumption of fruits, vegetables and whole grains, reduces the risk of chronic diseases associated with oxidative damage $[9,13]$. Carotenoids, tocopherols, ascorbates, lipoic acids and polyphenols are strong natural antioxidants with free radical scavenging activity. Endogenous antioxidant enzymes like super oxide dismutase (SOD), catalase, glutathione peroxidase, glutathione reductase, minerals like $\mathrm{Se}, \mathrm{Mn}, \mathrm{Cu}, \mathrm{Zn}$, vitamins $\mathrm{A}, \mathrm{C}$ and $\mathrm{E}$, carotenoids, limonoids and polyphenols exert synergistic actions in scavenging free radicals. Synthetic antioxidants (Fig. 1) such as butylated hydroxy anisole (BHA) and butylated hydroxy toulene (BHT) play a useful role in food and pharmaceutical industries $[14,15]$. The natural antioxidant system is mainly classified into two categories namely invitro and in-vivo antioxidants. On the basis of function they can be further divided into following four categories:<smiles>Cc1cc(C(C)(C)C)c(O)c(C(C)(C)C)c1</smiles>

1.1<smiles>COc1ccc(O)c(C(C)(C)C)c1</smiles>

1.2
Fig. (1). Synthetic Antioxidants. 1.1. Butylated hydroxyl toluene (BHT). 1.2. Butylated hydroxyl anisole (BHA). 
First line of defense comprises of preventive antioxidants such as glutathione peroxidase, glutathione reductase, SOD, catalase, selenoprotein, transferrin, ferritin, lactoferrin and non-enzymatic proteins etc., which suppress the formation of free radicals. They act by quenching of $\left[\mathrm{O}_{2}\right]^{-1}$, decomposition of $\mathrm{H}_{2} \mathrm{O}_{2}$ and sequestrations of metal-ions.

Second line of defense include the radical scavenging antioxidants mainly glutathione (GSH) and antioxidant phytochemicals. They act as free radical scavengers by suppressing chain initiation or breaking chain propagation.

Third line of defense are complex group of enzymes required for the repair of damaged proteins, DNA, oxidized lipids and these enzymes can stop chain propagation of peroxyl lipid radicals.

Fourth line of defense is an adaptation where signal for the production and reactions of free radicals and transport of the appropriate antioxidant to the right site at the tail end of disease where immunology plays an important role $[14,16]$.

Present review was with the objective to examine the available evidences for the involvement of natural antioxidants including carotenoids, tocopherols, ascorbates, lipoic acids and polyphenols in the maintenance of "redox homeostasis" in the redox regulation of normal physiological func- tions as well as pathogenesis of various diseases, including cancer, diabetes mellitus, inflammatory diseases, neurodegenerative disorders and ageing. The discussion was devoted to the various protective effects that may be provided by the antioxidants against the deleterious action of free radicals that play an important role in human health.

\section{Carotenoids}

Terpenes are the largest class of phytochemicals with carotenoids and limonoids being its two major subclasses. There are more than 700 naturally occurring carotenoids that act as biological antioxidants and protect cells and tissues from the damaging effects of free radicals. Carrots, tomatoes, parsleys, orange and green leafy vegetables like amaranth, chenopods, mustard, fenugreek, spinach, cabbage, radish and turnip are the rich sources of carotenoids (Fig. 2). They have been classified into two major groups on the basis of their structure- carotenes ( $\beta$-carotene, lycopene) containing only carbon and hydrogen that may be cyclic or linear and oxycarotenoids (xanthophylls, lutein) containing carbon, hydrogen and oxygen in the form of hydroxy, epoxy or oxy groups $[17,18]$. In carotenoids, the polyene chain contains up to 15 conjugated double bonds, which are responsible for their characteristic absorption spectra and specific photochemical properties. They are found in linear or all trans<smiles>[R]C1C=C(C)C(/C=C/C(C)=C/C=C/C(C)=C/C=C/C=C(C)/C=C/C=C(C)/C=C/C2=C(C)CC([R])CC2(C)C)C(C)(C)C1</smiles><smiles>[R]OC</smiles><smiles>[R]C1CC(C)=C(/C=C/C(C)=C/C=C/C(C)=C/C=C/C=C(C)/C=C/C=C(C)/C=C/C2=C(C)CC([R])CC2(C)C)C(C)(C)C1</smiles><smiles>[R]C(C=C(C)C)CC(C)=C/C=C\C(C)=C\C=C\C(C)=C\C=C\C=C(C)\C=C\C=C(C)\C=C\C=C(/C)CCC=C(C)C</smiles>

2.5<smiles>CC1=C(/C=C/C(C)=C/C=C/C(C)=C/C=C/C=C(C)/C=C/C=C(C)/C=C/C2=CC(=O)C(O)CC2(C)C)C(C)(C)CC(O)C1=O</smiles>

Fig. (2). Carotenoids. 2.1. $\alpha$-Carotene. 2.2. Lutein (Xanthophyll). 2.3. $\beta$-Carotene. 2.4. Zeaxanthin. 2.5. Lycopene. 2.6. Astaxanthin. 
configuration and exposure to light or heat facilitates the trans to cis isomerisation of one or more double bonds [19, 20].

Among the carotenes, only alpha, beta and epsilon carotenes possess vitamin A activity and out of them $\beta$-carotene is the most active. Natural $\beta$-carotene is the precursor of vitamin $\mathrm{A}$ and has preventive action against eye diseases and cancer. Carotenes enhance immune response and protect skin cells against UV radiations. They help to lower the risk of cardiovascular diseases, age related vision disorders, asthma and reduce inflammation [5, 9]. Lycopene gives tomatoes their red color and is particularly effective at quenching the destructive singlet oxygen. Along with carotene and lutein, it provides protection against lung, breast, uterus and prostate cancers. Green leafy vegetables and corn are best source of xanthophylls like lutein and zeaxanthin that are believed to function as protective antioxidants for the retinal part of human eye. Astaxanthin, a xanthophyll found in salmon, shrimp and other sea foods with potent antioxidant properties $[17,21,22]$. Limonoids, the second major subclass of terpenoids, are the biologically active phytochemicals present in citrus which act as antioxidant and protect lung tissues from free oxygen radicals. In vitro studies show that limonin, nomilin and limonoid glycosides have significant ability to inhibit proliferation of human breast cancer [23, 24].

Moreover, foods containing provitamin A carotenoids are the primary source of vitamin A in many countries, despite the poor bioavailability of carotenoids. In addition, epidemiologic studies suggest that dietary intake of carotenoids influences the risk for certain types of cancer, cardiovascular disease and other chronic diseases. Although it would be ideal to use humans directly to answer critical questions regarding carotenoids absorption, metabolism and effects on disease progression, appropriate animal models offer many advantages. Each potential model has strengths and weaknesses $[5,9,25]$. Like humans, gerbils, ferrets and preruminant calves all absorb $\beta$-carotene (bC) intact, but only gerbils and calves convert bC to vitamin A with efficiency similar to that of humans. Mice and rats efficiently convert bC to vitamin A but absorb carotenoids intact only when they are provided in the diet at supra physiologic levels. Mice, rats and ferrets can be used to study cancer, whereas primates and gerbils are probably more appropriate for studies on biomarkers of heart disease [25].

Epidemiologic studies indicate that an increased intake of fruits and vegetables that contain carotenoids is associated with a decreased risk of many types of cancer including lung, breast and those affecting the gastrointestinal tract [26-28], a decreased risk of cardiovascular disease [29], less incidences of age-related macular degeneration and reduction in xeropthalmia in areas with low preformed vitamin A (VA) intake [25, 30]. Consumption of certain fruits and vegetables has also been associated with a decreased risk of prostate cancer, and $\beta$-carotene (bC) supplementation has been shown to enhance natural killer cell activity in elderly humen [31-33]. In contrast, it has been reported that supplementation of bC either with or without VA to high risk populations that may increase the risk of lung cancer. These epidemiologic associations between carotenoids intake and risk of disease should be addressed to determine whether the carotenoids themselves are protective, or if carotenoids are markers for other protective factors in foods [33].

Many clinical studies indicate a protective effect. Inhibitory effects were reported in some studies using aberrant crypt foci, an intermediate lesion leading to colon cancer, as an end point and in mammary tumor studies, one using the dimethylbenz(a)anthracene model, and the other the spontaneous mouse model. Inhibitory effects were also reported in mouse lung and rat hepatocarcinoma and bladder cancer models. However, another report found no effect in the $N$ nitrosomethylurea-induced mammary tumor model when crystalline lycopene or a lycopene rich tomato carotenoids oleoresin was administered in the diet. This might be because of differences in routes of administration (gavage, intraperitoneal injection, intra-rectal instillation, drinking water, and diet supplementation), species and strain differences, form of lycopene (pure crystalline, beadlet, mixed carotenoids suspension), varying diets (grain-based, casein based) and dose ranges $(0.5-500 \mathrm{ppm})[33,34]$. Some other retrospective and prospective epidemiological studies indicate that tomato consumption $[31,35]$, lycopene intake [36, 37], and serum lycopene [38-40] levels are associated with decreased risk of cancers, most notably prostate and lung cancer. These epidemiological leads have stimulated a number of animal model and cell culture studies designed to test this hypothesis and to establish its biological plausibility. In addition, positive results have been reported in rat aberrant colon crypt formation and the rat hepatic preneoplasia model [41-44]. However, with regard to mammary tumorigenesis, results have proven ambiguous. Supplementing a semi purified diet with extremely low levels $5 \times 10-5 \%(0.5 \mathrm{ppm})$ of pure lycopene, showed significant inhibition of spontaneous mammary tumor development [45]. Using the dimethylbenz (a) anthracene (DMBA) model, Sharoni et al. [46] reported that intraperitoneal (ip) injections $(10 \mathrm{mg} / \mathrm{kg} \mathrm{bw}$, twice per week) of a tomato carotenoid mixture 2 weeks before DMBA administration to termination resulted in the inhibition of tumor multiplicity but had no effect on tumor incidence, volume, or latency. Cohen et al. $[41,47]$ using the $N$ nitrosomethylurea (NMU) model, reported no inhibitory effect on any parameter of tumor growth when a lycopene rich tomato carotenoids oleoresin (TCO) or pure lycopene fed in the diet to rats 250 and $500 \mathrm{ppm}(\mathrm{mg} / \mathrm{kg})$ throughout the experimental period. The discrepancies could be due to different routes of administration (ip injection, versus diet) and/or differences in carcinogens used (host-activated DMBA versus direct-acting NMU), and strain differences (outbred Sprague- Dawley [SD] versus inbred F-344). It is of interest that these results in the rat model were supported by two prospective human studies [48, 49], which showed no association between intake of fruits and vegetables and breast cancer risk.

\section{Vitamin E (Tocopherols and Tocotrie-nols)}

Vitamin E refers to a family of eight molecules having a chromanol ring (chroman ring with an alcoholic hydroxyl group) and a 12-carbon aliphatic side chain containing two methyl groups in the middle and two more methyl groups at the end. Tocopherols and tocotrienols are non-polar constituents of biological membranes that exist in nature in lipid phase. Tocopherols consist of a chromane ring and a long 
saturated phytyl chain. Tocopherols commonly known as tocols are 2-methyl-2-(4', 8', 12'- trimethyl tridecyl) chroman - 6-ols. When 3 double bonds are present at positions 3', 7' and $11^{\prime}$ of the side chain in tocols they are called tocotrienols. The $\alpha-, \beta-, \gamma$ - and $\Omega$ - tocols and tocotrienols differ in the number and position of methyl groups attached to the 5,7 and 8 position of the ring structure (Fig. 3). $\alpha$-tocopherol is the most abundant form, with high vitamin E activity and singlet oxygen quenching ability than other forms of tocopherols but is less effective in scavenging superoxide anion generated by xanthine oxidase $[18,33,50] . \gamma$-tocopherols can reduce the concentration of nitrogen dioxide most effectively that is involved in carcinogenesis, arthritis and neurologic diseases. Efficiency of scavenging hydroxyl, alkoxyl and peroxyl radicals by $\alpha$ - tocopherol is approximately $10^{10}$, $10^{8}$, and $10^{6}(\mathrm{M} / \mathrm{s})$ respectively $[19,51]$. Antioxidant mechanisms of tocopherols mainly involve the transfer of hydrogen at 6- hydroxyl group of a chromane ring, scavenging of free radicals and regeneration in the presence of ascorbic acid. Their phytyl chain adjusts itself in membrane bilayer while active chromane ring is closely positioned to the surface. This unique structure enables them to act as effective antioxidants and to be regenerated through reaction with other antioxidants [33, 52, 53].

The first dietary role discovered for tocopherol was as an essential nutrient for normal development of an animal foetus, hence, the name tos (Greek: childbirth), phero (Greek: to bring forth) and ol (alcohol). Tocopherol fertility restoration assays provided a basis for quantification, so-called "International Units" (IUs). The acetate of [dl]-alpha-tocopherol was arbitrarily assigned the value of one IU per milligram (mg).
The acetate and succinate derivatives are more stable, and hence more suited for storage and for use in supplements. Natural alpha tocopherol (RRR-alpha-tocopherol) had an activity of $1.49 \mathrm{IU}$ per $\mathrm{mg}$, whereas synthetic alphatocopherol (a racemic mixture of all $8=2^{3}$ stereoisomers) had an activity of one IU per mg. Beta, gamma and delta tocopherols had activities of $0.60 \mathrm{IU}, 0.30 \mathrm{IU}$ and $0.015 \mathrm{IU}$ per $\mathrm{mg}$, respectively. For alpha-tocopherol, the asymmetric carbon at the 2-position of the chromanol ring is the major (perhaps the only) determinant of the difference in biological activity [51-53].

Tocotrienols mainly found in palm oil, cereal grains and kale are also potential antioxidant and their mechanism of action is similar to tocopherols. They are associated with the reduced risk of cancer, Alzheimer's and cardiovascular diseases, cholesterol lowering ability and inhibited LDL oxidation $[8,33,52] . \alpha$-tocotrienol is preferentially absorbed as compared to its $\delta$ - and $\gamma$ - form. Even though tocotrienols have a higher radical scavenging activity than tocopherols but they are less bio-available as compared to the latter [25, 28]. Moreover, there are many biological functions of tocopherols, and the different forms do not have the same relative activities for each function. In the cancer prevention effect of Vitamin E studies it was stated that gammatocopherol was found most potent form for preventing breast cancer [49-53].

The biological activity of Vitamin $\mathrm{E}$ which attracts the most interest is the prevention of lipid peroxidation. Alphatocopherol is the most active tocopherol against peroxyl radicals (LOO) and delta-tocopherol is the least active (alpha>beta>gamma>delta). The anti-oxidant activity of Vita-<smiles>[R]c1c([R])c2c(c([R])c1O)CC[C@@H](CCC[C@H](C)CCC[C@H](C)CCCC(C)C)O2</smiles><smiles>[R]c1c([R3])c2c(c([R])c1O)CC[C@@H](C)O2</smiles>

$\begin{array}{llll} & \mathrm{R}_{1} & \mathrm{R}_{2} & \mathrm{R}_{3} \\ \text { 3.5 } & \mathrm{CH}_{3} & \mathrm{CH}_{3} & \mathrm{CH}_{3} \\ \text { 3.6 } & \mathrm{CH}_{3} & \mathrm{H} & \mathrm{CH}_{3} \\ \text { 3.7 } & \mathrm{H} & \mathrm{CH}_{3} & \mathrm{CH}_{3} \\ \text { 3.8 } & \mathrm{H} & \mathrm{H} & \mathrm{CH}_{3}\end{array}$

Fig. (3). Tocopherols and Tocotrienols. 3.1. $\alpha$-Tocopherol. 3.2. $\beta$-Tocopherol. 3.3. $\gamma$-Tocopherol. 3.4. $\delta$-Tocopherol. 3.5. $\alpha$-Tocotrienol. 3.6. $\beta$-Tocotrienol. 3.7. $\gamma$-Tocotrienol. 3.8. $\delta$-Tocotrienol. 
min $E$ is based on the ease with which the hydrogen on the hydroxyl group of the chroman ring can be donated to neutralize a free radical (creating a more stabile tocopheroxyl radical). As with phospholipids, the polar chroman ring tends to stay near the edges of the membrane, whereas the hydrophobic core will be buried deep into the membrane. When a phospholipid tail becomes peroxidized by a free radical, the tail becomes more polar and migrates to the surfaces where it can meet the tocopherol chroman ring to be neutralized, while forming a tocopheroxyl radical. The tocopheroxyl radical can be reduced (restored) to tocopherol directly by ubiquinol or vitamin $\mathrm{C}$ and then by glutathione or lipoic acid (via Vitamin $\mathrm{C}$ ), which are in turn reduced by $\mathrm{NADH}$ or NADPH. As an anti-oxidant which protects the membranes of cells and mitochondria, vitamin $\mathrm{E}$ would be expected to boost the immune system and to protect against cancer [18, $53,54]$. The main rationale for the use of vitamin $E$ to prevent atherosclerosis and coronary heart disease is based on the idea that $\alpha$-tocopherol prevents oxidation of LDL cholesterol. Better results were seen in a clinical trial that combined vitamin $\mathrm{E}$ with vitamin $\mathrm{C}$ presumably because the vitamin $\mathrm{C}$ provided a means to neutralize the tocopheroxyl radicals [18, 49-54].

\section{Ascorbic Acid}

Ascorbic acid (vitamin C) consists of a 6-carbon lactone ring with 2,3-enediol moiety and shows antioxidant activity due to enediol group. It is a leading natural antioxidant that can scavenge ROS and has anticarcinogenic effects $[55,56]$. It first changes to semi-dehydroascorbic acid by donating one hydrogen and an electron, followed by conversion into L-dehydroascorbic acid by donating a second hydrogen atom and electron (Fig. 4). Both L-ascorbic acid and L-dehydro ascorbic acid retain the vitamin $\mathrm{C}$ activity [19]. The antioxidant mechanism of ascorbic acid is based on hydrogen atom donation to lipid radicals, quenching of singlet oxygen and removal of molecular oxygen. Scavenging aqueous radicals and regenerating $\alpha$-tocopherol from the tocopheroxyl radical are also one of its well-known antioxidant properties. It is an excellent electron donor because of low standard one electron reduction potential, which makes generation of relatively stable semi-dehydro ascorbic acid possible and its easy conversion from dehydroascorbic acid to ascorbic acid
$[57,58]$. It can donate a hydrogen atom to a tocopheroxyl radical at the rate of $2 \times 10^{5} \mathrm{M} / \mathrm{s}$. Synthetic antioxidants were found less effective than ascorbic acid $[55,57]$. Oxidation of ascorbic acid is highly influenced by heat, light, water, $\mathrm{pH}$, oxygen concentration and metal ions like $\mathrm{Cu}^{+2}$ and $\mathrm{Fe}^{+3}$. It may be related to the prevention of some forms of cancer and heart diseases. Ascorbic acid and tocopherol supplementation can substantially reduce oxidative damage. Their effects are greater in non-smokers than in smokers. Smoking induces oxidative stress from numerous free radical compounds in the gaseous phase and the radicals formed from ascorbic acid act as pro-oxidant in smokers [8, 18, 59]. Moreover, ascorbate acts and an antioxidant by being itself available for energetically favourable oxidation. Oxidants (scientifically referred to as reactive oxygen species) and including hydroxyl ions, and hydrogen peroxide, contain an extra electron and thus are highly reactive and damaging to humans and plants at the molecular level. This is due to their interaction with nucleic acid, proteins and lipids. Reactive oxygen species can 'donate' their extra electron to ascorbate, which becomes monodehydroascorbate and soon gains another electron to become dehydroascorbate. The reactive oxygen species are reduced to water while the oxidized forms of ascorbate are relatively stable and unreactive, and do not causes cellular damage $[59,60]$.

In addition, ascorbic acid and glutathione (GSH) are important determinants of the intracellular redox state, and both are known to accelerate the decomposition of $\mathrm{S}$ nitrosoglutathione (GSNO), an endogenous adduct of nitric oxide (NO). The implications of these observations for GSNO bioactivity are not yet clear. The effect of ascorbic acid and GSH on GSNO bioactivity by using a bioassay with isolated segments of guinea pig aorta suspended in organ chambers, demonstrated arterial segments relaxation to GSNO $(0.1 \mathrm{mmol} / \mathrm{L})$ that was significantly enhanced by 300 $\mathrm{mmol} / \mathrm{L}$ ascorbic acid $(7166 \%$ versus $5366 \%, \mathrm{P}, 0.05)$ but not GSH. Both ascorbic acid and GSH significantly shortened the duration of arterial relaxation in response to $0.1 \mathrm{mmol} / \mathrm{L}$ GSNO, consistent with accelerated decomposition of GSNO. The effect of ascorbic acid was abrogated by the copper(I)specific agent bathocuproine but not deferoxamine, indicating a dependence on the availability of redox-active copper. Consistent with this notion, the action of ascorbic acid on

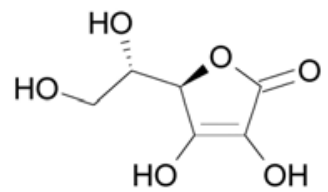

4.1

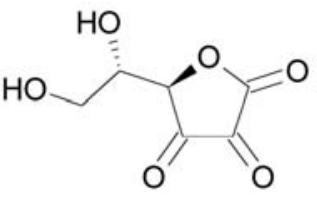

4.3

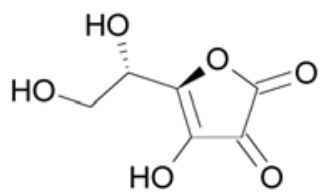

4.2

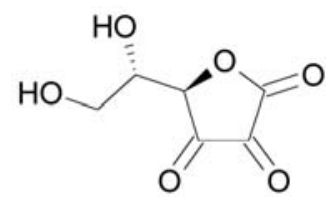

4.4

Fig. (4). Sequential 1-electron reduction of L-ascorbic acid. 4.1. Ascorbic acid. 4.2. Semi-dehydroascorbic acid. 4.3. Semidehydroascorbate radical. 4.4. Dehydroascorbic acid. 
GSNO bioactivity was also supported by copper-zinc superoxide dismutase, a physiologically relevant source of copper. In contrast, the effect of GSH on GSNO degradation and GSNO-mediated arterial relaxation was independent of transition metal ions. These data indicate that both ascorbic acid and GSH modulate GSNO bioactivity and suggest a distinction between the mechanism of GSNO degradation by ascorbic acid or GSH. Whereas both ascorbic acid and GSH accelerate the degradation of GSNO, only ascorbic acid is dependent on the presence of transition metal ions $[59,60]$.

\section{Lipoic Acids}

Some sulphur containing compounds like glutathione (GSH), lipoic acid (1, 2- dithilane-3-pentanoic acid) and dihydrolipoic acid (Fig. 5) present in meat, liver and heart show antioxidant activities. They prevent oxidative damage of proteins; regenerate GSH in liver, kidney and lung tissues. There are evidences to show that they reduce diabetic related complication and thus play an important role in reduction of blood glucose concentration. Lipoic acid improves mitochondrial membrane potential, age related memory loss and brain ailments, including Alzheimer's and Parkinson's disease [19, 61]. Racemic lipoic acid has been widely used in the treatment of cirrohosis, mushroom poisoning and in case of metal intoxication. Both oxidized (3-hydroxylipoic acid, 3-ketolipoic acid and bisnorlipoic acid) and reduced (dihydrolipoic acid) forms of lipoic acid (Fig. 5) act as antioxidants and have abilities for radical scavenging and metal chelation $[61,62]$.

Lipoic acid occurs in three different forms: R-lipoic acid ( $\mathrm{R}(+)$ enantiomer) is the only naturally-occurring form found in nature from the simplest organisms up to the humans. Life does not exist without it, and it is found in every cell of the body. S-Lipoic acid (S (-) enantiomer) is a by-product from chemical synthesis and may interfere with some the beneficial properties of the R-form, especially in interactions with proteins and enzymes. Alpha-lipoic acid consists of 50/50 racemic mixture of the $R$ and $S$ enantiomers and is the commonly commercially available form of lipoic acid. The antioxidant property of reduced form is due to the presence of two SH-moieties, which form 1, 2-thiolane groups on oxidation. The lone pair repulsion in the 1,2-dithiolane moiety of oxidized lipoic acid becomes less by reduction of the electron density in the ring system. The relative stability of the radical cation and the sulphoxide of lipoic acid are considerably increased and this explains the antioxidant activity of oxidized lipoic acid. Interaction of these forms with other antioxidants causes effective metabolic regeneration and gene regulation [52, 60-62]. R-Lipoic Acid (RLA) of it is recognized by the body due to the structure and design of the binding sites. The differences in activity of RLA, SLA and ALA are primarily due to stereospecific binding and competitive inhibition at the active sites of signaling proteins, transcription factors, histone acetylation/deacetylation and flavo-enzymes. RLA is a powerful antioxidant, a critical co-factor in ATP production, regulates lipid and carbohydrate metabolism, signal transduction and gene transcription. It is also neuroprotective, chelates heavy metals, can reverse enzyme and DNA oxidative damage and crosses the blood brain barrier. It has been shown to be more effective by a factor of 8-10 over the commercially available alpha lipoic acid for reducing inflammation. Within the mitochondria, RLA is reduced to R-DHLA, the more potent antioxidant, 28 times faster than SLA. It was also found more effective than SLA in enhancing insulin-stimulated glucose transport and metabolism in insulin-resistant rat skeletal muscle, and was also more effective than racemic alpha-lipoic acid and SLA in preventing cataracts in rats. Due to its essential role in health, alpha-lipoic acid may very well join the ranks of vitamins $\mathrm{C}$ and $\mathrm{E}$ as part of first-line of defense against free radicals $[61,62]$.

\section{Polyphenols}

The term polyphenols or phenolics refer precisely to those chemical compounds, which have an aromatic ring with hydroxyl substituent(s), including their derivatives like esters, methyl ethers and glycosides. On the basis of chemi-<smiles>NC(CCC(=O)NC(CS)C(=O)NCC(=O)O)C(=O)O</smiles>

5.1

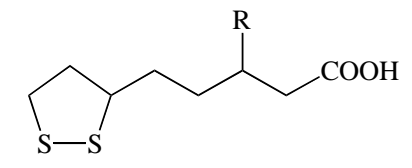

5.2

5.4<smiles>O=C(O)CCC1CCSS1</smiles>

5.5

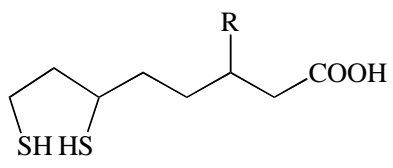

5.3

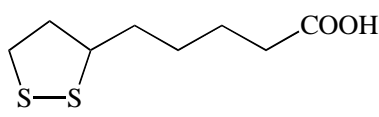

5.6

Fig. (5). Lipoic acids and its metabolites. 5.1. Glutathione. 5.2. Lipoic acid. 5.3. 3-Ketolipoic acid. 5.4. 3-Hydroxylipoic acid. 5.5. Bisnorlipoic acid. 5.6. Dihydrolipoic acid. 
cal structure, they can be classified into phenolic acids, flavonoids, stilbenes and lignans. They are the most abundantly occurring polyphenols in plants, of which flavonoids and phenolic acids accounts for about $60 \%$ and $30 \%$ of total dietary phenols respectively. Derivatives of hydroxybenzoic or hydroxycinnamic acids are the most common phenolic acids in plants. Protocatechuic acid, gallic acid, syringic acid and vanillic acid are some of the examples of phenolic acids derived from hydroxybenzoic acid while $p$-coumaric acid, caffeic acid and ferulic acid (Fig. 6) are derivatives of hydroxycinnamic acids [14, 16]. Ellagic acid (Fig. 7) a dimer of gallic acid is the most potent natural chemopreventive agent, which prevents oxidative damage of connective tissue and repairs damaged proteins present in the walls of blood vessels [63]. Antioxidant activity and biological properties of polyphenols from berries, red wine, ginkgo, onions, apples, grapes, chamomile, citrus, dandelion, green tea, hawthorn, licorice, rosemary, thyme, fruits, vegetables and beverages have been studied. They are rich sources of phenols that can enhance the efficacy of vitamin C, reduce the risk of cancer, act against allergies, ulcers, tumors, platelet aggregation and are also effective in controlling hypertension [11, 13, 64].

Flavonoids and their relatives are derived biosynthetically from the Shikimate pathway. They share a three-ring structure of two aromatic centers, ring $\mathrm{A}$ and $\mathrm{B}$ and a central oxygenated heterocycle moiety, ring $\mathrm{C}$ (Fig. 8). They have a flavone nucleus ( 2 phenyl-benzo- $\gamma$-pyrone) and on the basis of variation in the heterocyclic $\mathrm{C}$ ring may be classified into flavones, flavonols, flavanones, flavanols, isoflavones, anthocyanidins and proanthocyanidins. Chalcones such as butein, isoquirtigenin (Fig. 9) are considered to be members of the flavonoids, despite of lacking heterocycle ring C [15]. Flavones and flavonols have a double bond between C-2 and C-3 (Figs. $10 \&$ 11). Flavonols have a hydroxy group at the $\mathrm{C}-3$ position that is lacking in flavones. Flavanones and flavanols are characterized by the presence of a saturated three-carbon chain. Flavanols differ from flavanones by having a hydroxyl group at C-3 position (Figs. $12 \& 13$ ). Isoflavones (Fig. 14) are derived by cyclization of chalcones in such a way that the B ring is located at C-3 position. Anthocyanins (Fig. 15) are composed of aglycon called anthocynidins and sugar moiety(ies). Proanthocyanidins are condensed tannins or polymeric flavonols, which are generally formed as a result of coupling between electrophilic and nucleophilic flavanyl units $[16,65]$.<smiles>O=c1oc2c(O)c(O)cc3c(=O)oc4c(O)c(O)cc1c4c23</smiles>

Fig. (7). Ellagic acid.

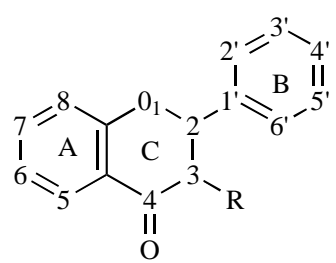

$\begin{array}{lll}\text { 8.1 } & \text { H } & \text { Double bond } \\ \text { 8.2 } & \text { OH } & \text { Double bond } \\ \text { 8.3 } & \text { H } & \text { Single bond } \\ 8.4 & \text { OH } & \text { Single bond }\end{array}$

Fig. (8). Basic flavonoidal structure. 8.1. Flavone. 8.2. Flavonol. 8.3. Flavanone. 8.4. Flavanol.

Flavonoids possess ideal structure for free radicals scavenging activity and have been found to be more effective<smiles>[R]c1cc([R])c(O)c([R])c1</smiles>

$\begin{array}{llll} & \mathrm{R} & \mathrm{R}_{1} & \mathrm{R}_{2} \\ \mathbf{6 . 1} & \mathrm{COOH} & \mathrm{OH} & \mathrm{H} \\ \mathbf{6 . 2} & \mathrm{COOH} & \mathrm{OH} & \mathrm{OH} \\ \mathbf{6 . 3} & \mathrm{COOH} & \mathrm{OCH}_{3} & \mathrm{OCH}_{3} \\ \mathbf{6 . 4} & \mathrm{COOH} & \mathrm{OCH}_{3} & \mathrm{H} \\ \mathbf{6 . 5} & \mathrm{CH}=\mathrm{CH} . \mathrm{COOH} & \mathrm{H} & \mathrm{H} \\ \mathbf{6 . 6} & \mathrm{CH}=\mathrm{CH} . \mathrm{COOH} & \mathrm{OH} & \mathrm{H} \\ \mathbf{6 . 7} & \mathrm{CH}=\mathrm{CH} . \mathrm{COOH} & \mathrm{OCH}_{3} & \mathrm{H} \\ \mathbf{6 . 8} & \mathrm{CH}=\mathrm{CH} . \mathrm{COO}-q u i n i c \text { acid } & \mathrm{OH} & \mathrm{H}\end{array}$

Fig. (6). Phenolic acids. 6.1. Protocatechuic acid. 6.2. Gallic acid. 6.3. Syringic acid. 6.4. Vanillic acid. 6.5. $p$-Coumaric acid. 6.6. Caffeic acid. 6.7. Ferulic acid. 6.8. Chlorogenic acid. 


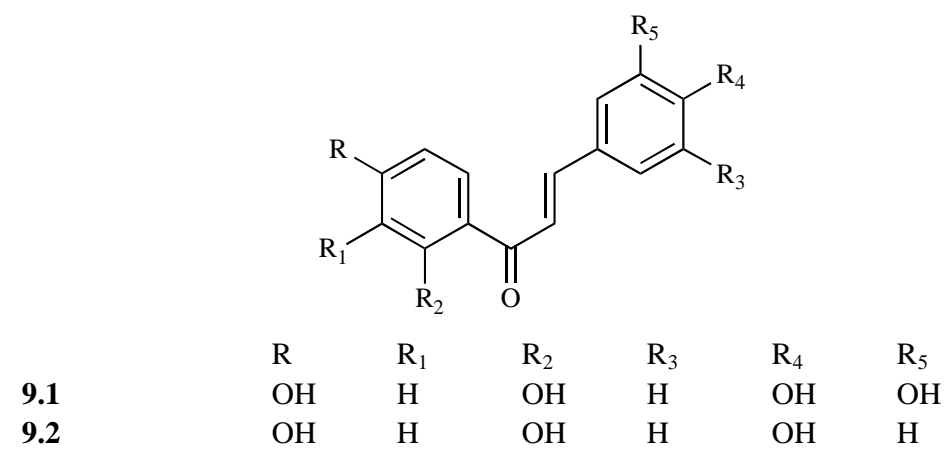

Fig. (9). Chalcones. 9.1. Butein. 9.2. Isoquirtigenin.<smiles>[R]c1cc(-c2cc(=O)c3c([R])c([R])c([R])c([R6])c3o2)cc([R3])c1[R]</smiles>

$\begin{array}{llllllll} & \mathrm{R} & \mathrm{R}_{1} & \mathrm{R}_{2} & \mathrm{R}_{3} & \mathrm{R}_{4} & \mathrm{R}_{5} & \mathrm{R}_{6} \\ \mathbf{1 0 . 1} & \mathrm{OH} & \mathrm{H} & \mathrm{OH} & \mathrm{H} & \mathrm{OH} & \mathrm{H} & \mathrm{H} \\ \mathbf{1 0 . 2} & \mathrm{OH} & \mathrm{H} & \mathrm{OH} & \mathrm{H} & \mathrm{OH} & \mathrm{H} & \mathrm{O}-\text {-Glucose } \\ \mathbf{1 0 . 3} & \mathrm{OH} & \mathrm{O}-\text { Glucose } & \mathrm{OH} & \mathrm{H} & \mathrm{OH} & \mathrm{H} & \mathrm{H} \\ \mathbf{1 0 . 4} & \mathrm{OH} & \mathrm{H} & \mathrm{OH} & \mathrm{H} & \mathrm{OH} & \mathrm{OH} & \mathrm{H}\end{array}$

Fig. (10). Flavones. 10.1. Apigenin. 10.2. Vitexin. 10.3. Isovitexin. 10.4. Luteolin<smiles>[R]c1cc(-c2oc3c([R6])c([R])c([R])c([R])c3c(=O)c2[R])cc([R3])c1[R4]</smiles>

$\begin{array}{lllllllll} & \mathrm{R} & \mathrm{R}_{1} & \mathrm{R}_{2} & \mathrm{R}_{3} & \mathrm{R}_{4} & \mathrm{R}_{5} & \mathrm{R}_{6} & \mathrm{R}_{7} \\ \mathbf{1 1 . 1} & \mathrm{OH} & \mathrm{H} & \mathrm{OH} & \mathrm{H} & \mathrm{OH} & \mathrm{H} & \mathrm{H} & \mathrm{OH} \\ \mathbf{1 1 . 2} & \mathrm{OH} & \mathrm{H} & \mathrm{OH} & \mathrm{H} & \mathrm{OH} & \mathrm{OH} & \mathrm{H} & \mathrm{OH} \\ \mathbf{1 1 . 3} & \mathrm{OH} & \mathrm{H} & \mathrm{OH} & \mathrm{H} & \mathrm{OH} & \mathrm{OH} & \mathrm{H} & \text { O-Glucose } \\ \mathbf{1 1 . 4} & \mathrm{OH} & \mathrm{H} & \mathrm{OH} & \mathrm{H} & \mathrm{OH} & \mathrm{OH} & \mathrm{H} & \text { O-Rutinose } \\ \mathbf{1 1 . 5} & \mathrm{OH} & \mathrm{H} & \mathrm{OH} & \mathrm{OH} & \mathrm{OH} & \mathrm{OH} & \mathrm{H} & \mathrm{OH}\end{array}$

Fig. (11). Flavonols. 11.1. Kaempferol. 11.2. Quercetin. 11.3. Quercetrin. 11.4. Rutin. 11.5. Myricetin.

antioxidants in vitro than tocopherols and ascorbates. They are efficient reducing agents that can stabilize the polyphenols derived radicals and delocalise the unpaired electrons. It has been reported that flavonoids with strong antioxidant activity are excellent hydrogen donors and have a 3', 4'dihydroxy configuration. Interestingly the hydroxyl groups on the chromane ring do not appear to participate directly in the redox chemistry. Instead it is the hydroxyl group of catechol moiety present in the B ring that donates or accepts hydrogen. However, while the flavonoids nucleus does not undergo direct redox modification, it does affect redox behaviour of substituents on B ring. Therefore, flavonoids containing catechol structure can exert a powerful radical scavenging activity. The position and number of hydroxyl groups also plays an important role in antioxidant activity. For ex- ample in apigenin (Figs. 10.1), the three-hydroxyl groups at position 5, 7, 4' were associated with a small but definite antioxidant effect, while kaempferol (Figs. 11.1) with an additional hydroxyl at position 3 was more potent than apigenin. Quercetin (Figs. 11.2) with additional hydroxyl group at $3^{\prime}$ and myricetin at $3^{\prime}, 5^{\prime}$ positions (Figs. 11.5) were still more effective $[15,18,65]$. Flavonoids can also generate $\mathrm{H}_{2} \mathrm{O}_{2}$ by donating a hydrogen atom from their pyrogallol or catechol structure to oxygen, through a superoxide anion radical. The pyrogallol-type compounds generate more $\mathrm{H}_{2} \mathrm{O}_{2}$ than that of catechol. $\mathrm{H}_{2} \mathrm{O}_{2}$ has been reported to raise levels of intracellular $\mathrm{Ca}^{2+}$, activate transcription factors, repress expression of certain genes, promote or inhibit cell proliferation, be cytotoxic, activate or suppress certain signal transduction pathways, promote or suppress apoptosis $[12,66]$. 
<smiles>Oc1cc(O)c2c(c1)O[C@H](c1ccc(O)c(O)c1)[C@H](O)C2</smiles>

12.1<smiles>O=C(O[C@@H]1Cc2c(O)cc(O)cc2O[C@H]1c1ccc(O)c(O)c1)c1cc(O)c(O)c(O)c1</smiles>

12.3<smiles>Oc1cc(O)c2c(c1)O[C@H](c1ccc(O)c(O)c1)[C@H](O)C2</smiles>

12.2<smiles>O=C(O[C@H]1Cc2c(O)cc(O)cc2O[C@@H]1c1ccc(O)c(O)c1)c1cc(O)c(O)c(O)c1</smiles>

12.4

Fig. (12). Flavanols (Flavan-3-ols). 12.1. Catechin. 12.2. Epicatechin. 12.3. Catechin gallate. 12.4. Epicatechin gallate.

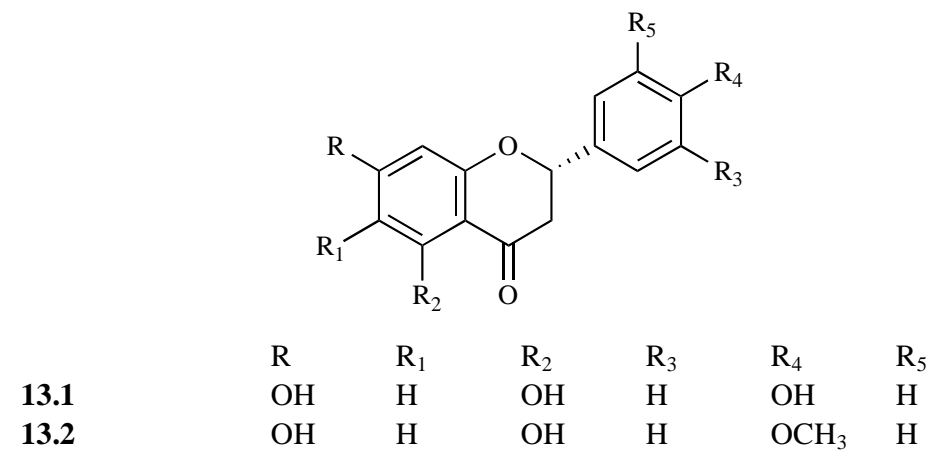

Fig. (13). Flavanones. 13.1. Naringenin. 13.2. Hesperidin.

More than 4000 flavonoids have been identified in plants, which are responsible for the color of vegetables, fruits, grains, seeds, leaves, flowers, bark and products derived from them [13, 14, 19]. Luteolin (Fig. 10.4), kaempferol, quercetin, quercitrin, rutin, myricetin (Fig. 11) and vitamin $\mathrm{C}$ (Fig. 4.1) are powerful antioxidants that inhibit the oxidation of low-density lipoprotein (LDL), a major factor in the promotion of atherosclerosis, which is the plaque build up in arteries that can lead to heart attack or stroke. In general, the aglycones were found with greater antioxidant potential than their glycosides [9, 12]. Use of comet assay to assess DNA damage during oxidative stress showed that quercetin was more potent antioxidant as compared to rutin and vitamin $\mathrm{C}$. Isoflavones like daidzein (Fig. 14.1) and genestein (Fig. 14.2) found abundantly in legumes such as lentils, chickpeas and soybeans, have nutraceutical properties against tumor growth and cancer and they form one of the main classes of oestrogenic substances in plants. Anthocyanins, another major group of flavonoids play a significant role in collagen protein synthesis and sport medicines. Athletes who exercise a lot produce free radicals that can be tackled by anthocyanidins $[2,67]$.<smiles>[R]c1cc2occ(-c3ccc(O)cc3)c(=O)c2c([R])c1[R]</smiles>

$\begin{array}{llll} & \mathrm{R} & \mathrm{R}_{1} & \mathrm{R}_{2} \\ \mathbf{1 4 . 1} & \mathrm{OH} & \mathrm{H} & \mathrm{OH} \\ & \mathrm{OH} & \mathrm{H} & \mathrm{H}\end{array}$

Fig. (14). Isoflavones. 14.1. Daidzein. 14.2. Genistein.

\section{Antioxidant Activity}

Flavonoids are powerful metal chelators and scavengers of free radicals and also act as anti-inflammatory, anti-ulcer, antitumor and anticancer agents. They act as potent chainbreaking antioxidants and possess vitamin $\mathrm{C}$ stabilizing activity by increasing its absorption. Their activity depends upon the arrangement of functional groups in nuclear structure $[1,65]$. They interact with cellular signal pathways that control cell cycle, differentiation and apoptosis. Their antineoplastic effects can improve antioxidant activity, induction 


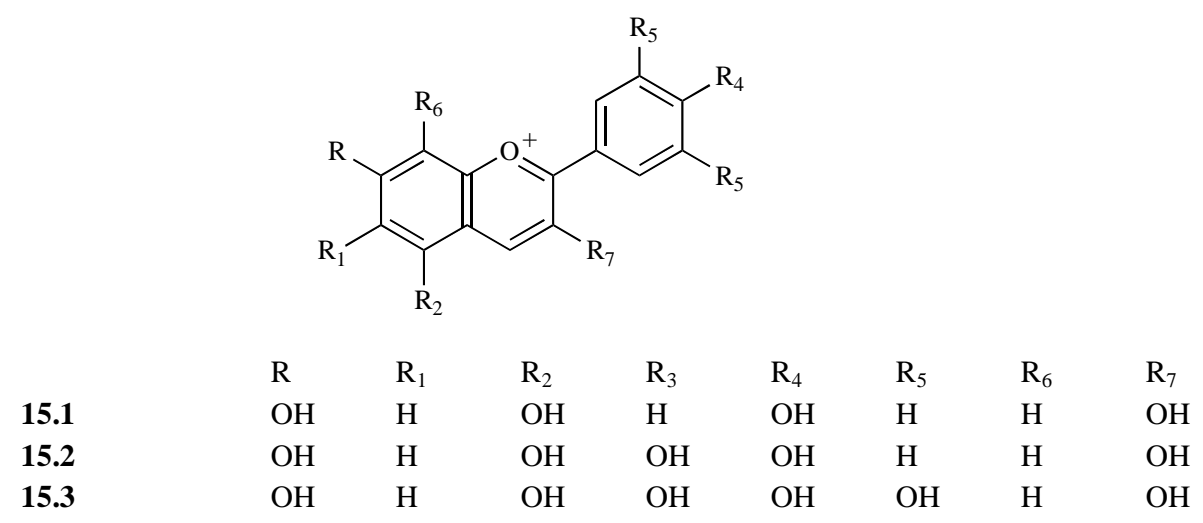

Fig. (15). Anthocyanins. 15.1. Pelargonidin. 15.2. Cyanidin. 15.3. Delphinidin.

of phase II enzyme activity, inhibition of protein kinases and interaction with type II estrogen binding sites [15, 68]. Therapeutic usefulness of flavonoids has been demonstrated in gastrointestinal hemorrhages, radiation reactions, ethyroblastosis, menorrhagia, bleeding cystitis, tuberculoses, hemophysis, periodontal diseases, epitasis and ophthalmic disorders $[69,70]$.

The antioxidant activity of flavonoids can be explained through their chelating action (Fig. 16). They bind with transition metal particularly iron and copper and thus inhibit of transition metal-catalysed free radical formation. The two most likely points of attachment of transition metal ions to the flavonoids are the $o$-diphenolic groups at the $3^{\prime}, 4^{\prime}$,dihydroxy positions in the $\mathrm{B}$ ring and the ketol structures, 4keto, 3-hydroxy or 4-keto, 5-hydroxy in the $\mathrm{C}$ ring. Chelated in this way, transition metals would be unavailable to interact with other compounds and initiate biologically damaging reactions. Flavonoids inhibit lipid peroxidation, oxidation of linoleic acid and $\mathrm{Fe}^{+2}$ catalyzed oxidation of glutamine synthase, through free radical scavenging and removal of metal ions from catalytic sites via chelation $[15,71,72]$. The electron and $\mathrm{H}^{+}$donating capacity of flavonoids seem to contribute in the termination of lipid peroxidation chain reaction based on their reducing power. Due to their reducing power these phytochemicals act as both antioxidant and pro-oxidant depending upon the exposed environment. They act as prooxidant in the absence of free radicals. The classical antioxidants, $\alpha$-tocopherol and vitamin $\mathrm{C}$, are also reported to behave in a similar fashion. Catechins, abundant in green tea, also possess the antioxidative and pro-oxidative characteristics of $\mathrm{Cu}^{+2}$ induced LDL oxidation. In the initiation phase, LDL oxidation was inhibited by the addition of catechins (Fig. 12.1). In contrast, during the propagation phase of LDL oxidation, it served as accelerators of oxidation [15, 18, 73].

Flavonoids are also known to modify the activities of enzymes like protein kinase $\mathrm{C}$, protein tyrosine kinase, aldose reductase, myeloperoxidase, NADPH oxidase, xanthine oxidase, phospholipase, reverse transcriptase, ornithine decarboxylase, lipoxygenase, and cycloxygenase. Some of these enzymes are involved in immune functions, carcinogenesis, cellular transformations, tumor growth and metastasis. The antioxidant function and enzyme modifying actions of flavonoids account for many of their pharmacological activities [29, 74].

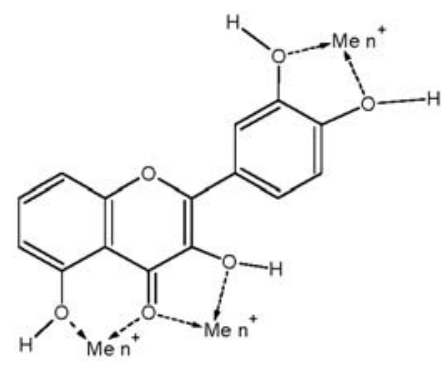

Fig. (16). Chelation of transition metals with flavonoids $\left[\mathrm{Me}^{\mathrm{n}+}=\right.$ Transition metal ions like $\left.\mathrm{Fe}^{+2}, \mathrm{Cu}^{+}\right]$.

\section{Biological Activity}

Biological effects of phenols are of great interest since evidences were found that they offer protection against gastro-duodenal pathogenesis, premature aging, inflammation, metabolic dysfunction, cancer, neuro-degenerative and cardiovascular diseases. Polyphenols have the potential to inhibit oxidation of LDL in vitro that is considered to be a key mechanism in atherosclerosis. Certain studies have shown that the consumption of beverages and foods rich in polyphenols resulted in reduced susceptibility of LDL to oxidation induced in ex vivo by $\mathrm{Cu}^{+2}$. Flavonoids are effective scavengers of free radicals, responsible for DNA damage and tumor promotion. Their anticarcinogenic activity is expressed by multiple mechanisms, like activating and enhancing activities of antioxidant enzymes or by inhibiting certain enzymes such as P-450 found in the liver. They metabolize a significant number of carcinogens and play a major role in the activation of carcinogens, such as polycyclic hydrocarbons and heterocyclic amines $[1,7,75,76]$.

Flavonoids were found to have beneficial effect in rheumatoid arthritis and experimental studies showed their antiinflammatory activity. It has been reported that flavonols and flavone inhibit cytochrome P-450 enzymes while genistein and quercetin inhibit protein tyrosine kinase involved in cell proliferation. Catechins affect cell-signaling and cell cycle progression by inhibiting signal transduction pathways mediated by epidermal and platelet-derived growth factors favorably. Apigenin, luteolin and quercetin have been shown to cause cell cycle arrest and apoptosis by p53-dependent mechanism $[7,75,76]$. Thus multiple mechanisms have been identified for the anti-neoplastic effects of flavonoids, including anti-inflammatory and anti-proliferative. However, 
these effects were often obtained with concentrations, which are greater than what can be achieved in humans through dietary means [9, 67]. Extracts from Silybum marianum have been used for centuries in folk medicine for the treatment of liver disorders. Silybin, the main flavolignan occurring in the flavonoids mixture silymarin of this plant had shown positive effect on liver. Kolaviron from seeds of the Garcinia kolu and hispidulin from Buccuris frimeru have also been reported as hepatoprotective $[9,69,70,77,78]$.

\section{Dietary Polyphenols}

Epidemiological studies provide convincing evidence that diet rich in antioxidants is associated with a lower incidence of degenerative diseases. Cereals, legumes (barley, corn, nuts, oats, rice, sorghum, wheat, beans, and pulses), oilseeds (rapeseed, canola, flaxseed and olive seeds), fruits, vegetables and beverages (fruit juices, tea, coffee, cocoa, beer and wine) are the main sources of dietary polyphenols $[12,13,14,79-85]$. Fruits like apple, grape, pear, cherry and various berries contain up to $200-300 \mathrm{mg}$ polyphenols per $100 \mathrm{~g}$ fresh weights. A glass of red wine or a cup of coffee or tea contains about $100 \mathrm{mg}$ polyphenols. Their total dietary intake may be about $1 \mathrm{~g}$ per day, which is about 10 times higher than that of vitamin $\mathrm{C}$ and 100 times higher than those of vitamin $\mathrm{E}$ and carotenoids $[11,59,86]$. The major constituents of tea polyphenols are flavonols (catechin, epicatechin, catechin gallate and epicatechin gallate), flavanols (quercetin, kaempferol and their glycosides), flavones (vitexin, isovintexin) and phenolic acids (gallic acid, chlorogenic acid). They constitute up to $30 \%$ of the dry weight of green leaves and $9-10 \%$ of the dry weight of black tea leaves $[14,74,87]$. Ferulic acid is associated with dietary fiber linked with hemi cellulose of the cell wall via ester bonds. Caffeic acid in the form of caffeoyl esters and coumaric acids are common in apples, pears, and grapes. In addition, apples and pears are rich in chlorogenic acid and grape in gallic acid. Apples contain high levels of quercetin among fruits $[83,87,88]$. Grain-derived products are very important in human diet as they have higher concentration of phenolic acids in the outer layers of kernel that constitute the bran [89, 90]. Most of the phenolic acid derivatives are hydrolysable tannins and are usually esterified with glucose [90-92]. Citrus fruits are main sources of flavonones and hesperidin is found in abundance (120 -250 mg/lit) in orange juice [23, 93, 94]. Quercetin occurs in its glycosylated form as rutin in fruits, vegetables and particularly onions are its rich source $[13,16,81,82]$. Anthocyanins are pigments of fruits such as cherries, plums, strawberries, raspberries, balck berries and red currant and their content varies from 0.15 to $4.5 \mathrm{mg} / \mathrm{g}$ in fresh berries. Occurrence of some of the flavonoids is restricted to a few foodstuff like the main source of isoflavonoid is soy, which contain $\sim 1 \mathrm{mg} / \mathrm{g}$ of genistein and daidzein and have received considerable attention due to their suggested role in prevention of cancer and osteoporosis. People who consume traditional diets rich in soy and tea rarely experience breast, uterus and prostate cancer. Although there are a range of potentially antimutagenic fruits, vegetables and cereals but their intake is generally below the level necessary to protect from various mutagens [20, 67, 77, 82, 83].

\section{Randomized Clinical Trails (RCTs)}

In a clinical study [95], randomized, single-blind trial conducted among 180 patients (99 males and 81 females) with the metabolic syndrome, in the intervention group $(\mathrm{n}=$ 90) were instructed to follow a Mediterranean-style diet and received detailed advice about how to increase daily consumption of whole grains, fruits, vegetables, nuts, and olive oil. Patients in the control group $(\mathrm{n}=90)$ followed a prudent diet (carbohydrates, 50\%-60\%; proteins, 15\%-20\%; total fat, $<30 \%)$. Nutrient intake; endothelial function score as a measure of blood pressure and platelet aggregation response to L-arginine; lipid and glucose parameters; insulin sensitivity; and circulating levels of high-sensitivity C-reactive protein (hs-CRP) and interleukins 6 (IL-6), 7 (IL-7), and 18 (IL18). After 2 years, patients following the Mediterraneanstyle diet consumed more foods rich in monounsaturated fat, polyunsaturated fat, and fiber and had a lower ratio of omega- 6 to omega-3 fatty acids. Total fruits, vegetables, and nuts intake (274 g/d), whole grain intake (103 g/d), and olive oil consumption $(8 \mathrm{~g} / \mathrm{d})$ were also significantly higher in the intervention group. The level of physical activity increased in both groups by approximately $60 \%$, without difference between groups. Body weight decreased more in patients in the intervention group $(-4.0 \mathrm{~kg})$ than in those in the control group $(-1.2 \mathrm{~kg})$. Compared with patients consuming the control diet, patients consuming the intervention diet had significantly reduced serum concentrations of hs-CRP, IL-6, IL7, and IL-18, as well as decreased insulin resistance. Endothelial function score improved in the intervention group change +1.9 but remained stable in the control group +0.2 . At 2 years of follow-up, 40 patients in the intervention group still had features of the metabolic syndrome, compared with 78 patients in the control group. A Mediterranean-style diet might be effective in reducing the prevalence of the metabolic syndrome and its associated cardiovascular risk [95]. In another single-blind intervention trial [96], 406 patients 24 to 48 hours after acute myocardial infarction (AMI) were assigned to either diet A (204 patients, group A) or B (202 patients, group B) for 6 weeks. Group A received significantly lower calories, a higher vegetables, fish proteins, polyunsaturated fatty acids, and a higher polyunsaturated/saturated fat ratio diet than did group B (higher total calories and saturated fatty acids). Group A also received less dietary cholesterol, salt, caffeine, and higher soluble dietary fiber, vitamins and minerals than did group B. After 6 weeks, group A had a significant decrease in mean serum total $(-20.5 \mathrm{vs}-8.6 \mathrm{mg} / \mathrm{dl})$ and low-density lipoprotein $(-16.6$ vs $-6.4 \mathrm{mg} / \mathrm{dl})$ cholesterols, and triglycerides (-15.5 vs -7.6 $\mathrm{mg} / \mathrm{dl}$ ), with no decrease in high-density lipoprotein cholesterol $(-1.5 \mathrm{vs}-1.3 \mathrm{mg} / \mathrm{dl})$ compared with the initial levels and changes in group B. Group A also had a greater decrease in mean body weight (3.4 vs $1.3 \mathrm{~kg}$ ) than that of group B [96]. To test whether a fat reduced diet rich in soluble dietary fibre, antioxidant vitamins, and minerals reduces complications and mortality after acute myocardial infarction [97]. A randomised, single blind, controlled trial performed on 505 patients with suspected acute myocardial infarction (AMI). Those with definite or possible AMI and unstable angina based on WHO criteria were assigned to diet A $(n=204)$ or diet B $(n=202)$ within $24-48$ hours of infarction. Both groups were advised to follow a fat reduced diet. Group 
A was also advised to eat more fruits, vegetables, nuts, and whole grain products. Blood lipoprotein concentrations and body weight fell significantly in patients in group A compared with group B (cholesterol fell by $0.74 \mathrm{mmol} / \mathrm{l}$ in group A v $0.32 \mathrm{mmol} / \mathrm{l}$ in group B, $95 \%$ confidence interval of difference 0.14 to 0.70 , and weight by $7.1 \mathrm{v} 3.0 \mathrm{~kg}, 0.52$ to 7.68). The incidence of cardiac events was significantly lower in group A than group B (50 v 82 patients, $\mathrm{p}<0.001)$. Group A also had lower total mortality than group B. Comprehensive dietary changes in conjunction with weight loss immediately after acute myocardial infarction may modulate blood lipoproteins and significantly reduce complications and mortality [97]. In a randomized, placebocontrolled trial [98], the effects of treatment with fish oil (eicosapentaenoic acid, $1.08 \mathrm{~g} /$ day) and mustard oil (alphalinolenic acid, $2.9 \mathrm{~g} /$ day) were compared for 1 year in the management of 122 patients (fish oil, group A), 120 patients (mustard oil, group B), and 118 patients (placebo, group C) with suspected AMI. Treatments were administered about 18 hours after the symptoms of AMI in all three groups. After 1 year total cardiac events were significantly less in the fish oil and mustard oil groups compared with the placebo group (24.5\% and $28 \%$ vs. $34.7 \%, \mathrm{p}<0.01)$. Nonfatal infarctions were also significantly less in the fish oil and mustard oil groups compared with the placebo group $(13.0 \%$ and $15.0 \%$ vs. $25.4 \%, \mathrm{p}<0.05)$. Total cardiac deaths showed no significant reduction in the mustard oil group; however, the fish oil group had significantly less cardiac deaths compared with the placebo group $(11.4 \%$ vs. $22.0 \%$, p < 0.05$)$. Reductions in blood lipoproteins in the two intervention groups were modest and do not appear to be the cause of the benefit in the two groups. Diene conjugates showed a significant reduction in the fish oil and mustard oil groups, indicating that a part of the benefit may be caused by the reduction in oxidative stress. The findings of this study suggest that fish oil and mustard oil, possibly due to the presence of $\omega-3$ fatty acids, may provide rapid protective effects in patients with AMI [98]. However, a broad study based on detailed scientific evidences is necessary to confirm such type of suggestions and claims. AMI is associated with endothelial dysfunction and tachycardia, characterized with hyperglycaemia, hyperinsulinaemia, hypertriglyceridaemia, free radical stress, rise in pro-inflammatory cytokines, and free fatty acids and which are predisposing factors for disruption of atheroma plaques, known to result in re-infarction and death [99]. Consumption of fruits, vegetables, and nuts [100] was protective against the risk of myocardial infarction, increased consumption of pro-inflammatory macronutrients such as $\omega$ 6 fatty acids, trans fatty acids, saturated fatty acids, as well as refined carbohydrates may produce oxidative stress (OS). Further, consumption of high vegetables and fruits rich in natural antioxidants largely prevent the negative effects on endothelial function. Intervention trials, in 605 patients who had a myocardial infarction were randomly assigned to a 'Mediterranean-style' diet or a control low-fat diet. After a mean follow-up of 27 months, the risk of new AMI and episodes of unstable angina as well as total mortality were reduced by $70 \%$ by the Mediterranean diet $[99,100]$. Lactate dehydrogenase (LDH) level increased less in the intervention group than in the control group, indicating that myocardial damage was prevented by the cardio-protective diet. Total cardiac events, including fatal and non-fatal myocardial in- farctions and sudden cardiac deaths, were significantly lower in the intervention group when compared with the control group, both after 6 weeks as well as after 1 year [101]. These intervention trials indicate that further studies should be conducted with Columbus diet and oils in patients with AMI, to demonstrate mechanisms more scientifically, in the pathophysiology of complications and deaths, among these patients. It is therefore suggested that a western diet should be avoided in patients with AMI, and a diet, which is beneficial to vascular endothelium and myocardium should be administered. Inclusion of high fiber foods such as oats, fruits and vegetables in the diet can decrease fat intake and modulate blood lipids. To test this hypothesis, 61 group A and 59 group B patients with essential hypertension were administered guava fruit preferably before meals in a randomized and single-blind fashion for 12 weeks [102]. A significant net decrease in serum total cholesterol $(9.9 \%)$, triglycerides $(7.7 \%)$ and blood pressures $(9.0 / 8.0 \mathrm{~mm} \mathrm{Hg})$ with a significant net increase in high-density lipoprotein cholesterol (8.0\%) was observed after 12 weeks of guava fruit substitution in group A than in group B. The addition of guava fruit in the usual diet might be responsible for providing significant amounts of soluble dietary fiber and antioxidant vitamins and minerals responsible for the observed beneficiary effects. The efficacy of the administration of fruits and vegetables [103] for 12 weeks as an adjunct to a prudent diet in decreasing blood lipids in 310 (intervention; group A) and 311 (control; group B) patients with risk factors of coronary artery disease $(C A D)$ in a parallel, single-blind fashion was studied. It was found that fruits and vegetables rich diet decreased total cholesterol level by $6.5 \%$ and low-density lipoprotein cholesterol level by $7.3 \%$ in group A as compared to group B. The high-density lipoprotein, cholesterol levels that decreased during the diet stabilization period in both groups, increased by $5.6 \%$ in group A after 12 weeks. Serum triglycerides also decreased (7\%) more in group A than B. Fasting blood glucose decreased by $6.9 \%$ in group A and by $2.6 \%$ in group $\mathrm{B}$. The combined effect of a fat-modified diet plus fruits and vegetables was greater than these changes. The Diet and Moderate Exercise Trial (DAMET) is a randomized and controlled study [104] on risk factors of coronary heart disease (CHD) in 231 group A and 232 group B patients with risk factors of CHD were administered a prudent diet for 4 weeks. Group A patients in addition were also given at least $400 \mathrm{~g} /$ day of fruits and vegetables that are rich in dietary fibre and antioxidants such as vitamins A, C, E, carotene and copper, selenium and magnesium. After 4 weeks, group A patients also did moderate exercise and group B without exercise for another 20 weeks. After a follow-up period of 24 weeks, adding exercise to diet was associated with a significant decrease in blood total cholesterol (8.9\%) and LDL-cholesterol (6.7\%) and triglycerides (11.9\%) and a marked increase in HDLcholesterol (16.5\%). Mean blood pressures, fasting blood glucose, body weight, body mass index, waist-to-hip ratio and subcutaneous fat also showed a significant decrease in group A, leading to a significant decrease in 12-year CHD risk. A long-term follow-up based on scientifc merit is necessary to demonstrate the role of such approach in decreasing cardiovascular morbidity and mortality. Ischaemic heart disease remains a major cause of mortality in developed countries [105]. A number of important risk factors 
for the development of coronary atherosclerosis have been identified including hypertension, hypercholesterolaemia, insulin resistance and smoking. However, these factors can only partly explain variations in the incidence of disease either between populations or within populations over time. In addition, population interventions based upon these factors have little impact in the primary prevention of heart disease. Recent evidences suggest that one of the important mechanisms predisposing to the development of atherosclerosis is oxidation of the cholesterol-rich low-density lipoprotein particle. This modification accelerates its uptake into macrophages, thereby leading to the formation of the cholesterol-laden 'foam cell'. In vitro, low-density lipoprotein oxidation can be prevented by naturally occurring anti-oxidants such as vitamins $\mathrm{C}, \mathrm{E}$ and $\beta$-carotene. These dietary antioxidants may influence the rate of progression of coronary atherosclerosis in vivo and discusses the need for formal clinical trials of antioxidant therapy.

\section{Randomized Clinical Trails (RCTs) on Antioxidant Vitamins}

Large, prospective cohort studies of [106] suggested that, overall there is a lower risk of cardiovascular disease for vitamin $\mathrm{E}$ users. However, there were several inconsistencies in the data. One study clearly identified that higher doses of vitamin E supplements for prolonged periods of time (100 IU for at least 2 years) was protective. In contrast, another study did not find a protective effect in women taking vitamin E supplements, although it identified vitamin E from food sources to be potentially protective. Similarly, some of the RCTs showed vitamin E to be a potentially promising intervention in preventing cardiovascular disease, although its benefit was not clearly and conclusively demonstrated. Although a large number of ongoing randomized trials were looking at the effect of vitamin E supplements in both primary and secondary prevention, which may help to clarify the situation. The evidence from large, prospective epidemiological studies of $\beta$-carotene (pro vitamin A) was somewhat inconsistent, but did suggest the possibility of lower adverse cardiovascular outcomes; in particular, for men who are current or former smokers, and who consume large amounts of dietary $\beta$-carotene provided by nutritional sources or vitamin supplements. Some of the studies also suggested an association between high $\beta$-carotene intake and a lower risk of cancer, particularly lung cancer. Evidences from RCTs failed to demonstrate any benefit for $\beta$-carotene supplementation at adequate doses, even for prolonged periods of time. Certain studies also highlighted concern that an increased risk of cancer was evident; in particular, one large trial amongst smokers ( $\beta$-Carotene and Retinol Efficacy Trial, RET) was terminated earlier than planned due to an increase in lung cancer amongst individuals randomized to receive $\beta$-carotene and vitamin A [106]. The evidence from epidemiological studies was inconclusive and did not clearly identify vitamin $\mathrm{C}$ intake as a significant protective factor against cardiovascular disease. In addition, few RCTs rigorously assessed the effects of vitamin $\mathrm{C}$ supplements. In a trial on 578 geriatric patients, which assessed the use of $200 \mathrm{mg}$ vitamin $\mathrm{C}$ supplements found that mortality was not reduced after 6 months. In another trial, that examined the effect of a combination of vitamin $\mathrm{C}$ and molybdenum, failed to find a reduction in overall mortality or mortality from cardiovascular disease [106]. Prospective epidemiological investigations suggested that there was a reduction in cardiovascular risk associated with an increased intake of antioxidant vitamins, particularly vitamin E. RCTs remain inconclusive with regard to the role of vitamin $\mathrm{E}$ in cardiovascular protection. The RCTs of $\beta$-carotene in primary prevention showed no effect associated with the use of $\beta$-carotene, and possibly a potential for harm. There were inconclusive and insufficient epidemiological and clinical trial data with regard to the role of vitamin C in cardiovascular protection.

\section{CONCLUSIONS}

Reactive oxygen species (ROS) and reactive nitrogen species (RNS) are products of normal cellular metabolism. ROS and RNS are known to act as secondary messengers controlling various normal physiological functions of the organism and therefore the production of NO by NOS and superoxide by nicotinamide adenine dihydrogen phosphate (NADPH) is tightly regulated by hormones, cytokines, and other mechanisms. In addition, ROS and RNS participate in various redox-regulatory mechanisms of cells in order to protect cells against oxidative stress and maintenance of cellular "redox homeostasis". Overproduction of ROS, most frequently either by excessive stimulation of NADPH by cytokines, or by the mitochondrial electron transport chain and xanthine oxidase result in oxidative stress. Oxidative stress is a deleterious process that can be an important mediator of damage to cell structures and consequently various disease states and ageing. ROS appear to be key regulatory factors in molecular pathways linked to neurodegenerative and cardiovascular diseases development which offer potential therapeutic invention points. For example specific understanding of the regulation of antiproliferative pathways by phytochemicals of nutraceutical importance such as carotenoids, flavonoids, polyphenols, tocopherols and other potent natural products and their role to control several diseases induced by oxidative stress might aid in the design of novel therapies targeting the respective molecular pathways. Since continued research is needed to better understand the mechanisms and specific pathways involved in ROS-induced diseases, and to determine the most rational and effective combination of antioxidants. Despite the problems associated with extrapolating from animal models to humans, controlling for these variables in future feeding studies should provide more definitive answers to the question of the anticancer, antidiabetic, anti-ulcer, anti-inflammatory and antimutagenic effects as of carotenoids, flavonoids polyphenols, tocopherols, and other potent natural products. Several clinical evidences, together with epidemiologic observations, suggest that for example tomato consumption may have organ-specific chemopreventive effects with antioxidative phytomolecules exerting protective effects on to tumour development, tumour dissemination, neurodegenerative and cardiovascular diseases. Hence, most of the data on free radical biology have been generated from in vitro studies and need to be verified in vivo. The recent advances in biochemistry and molecular biology techniques provide new, powerful tools for studying the expression of tissue antioxidant enzymes and for elucidating the mechanisms of the actions of antioxidants. Thus the future of antioxidants hold a great promise to ensure a better disease free lifestyle for the man- 
kind by scavenging free radicals and consequently preventing mutagenic changes and associated disorders.

In a number of clinical trials the importance of daily consumption of whole grains, fruits, vegetables, nuts, and unsaturated fatty acids rich vegetable oils with controlled diets in the prevention or treatment of various diseases have been described. However, broad studies based on detailed scientific evidences and detailed mechanisms of their action are necessary to confirm such type of suggestions and claims. Further, a long-term follow-up is also necessary to demonstrate the role of such approaches in decreasing oxidative stress and associated disorders. Randomized clinical trails (RCT) and evidences from epidemiological studies on naturally occurring antioxidant vitamins such as vitamins $\mathrm{C}, \mathrm{E}$ and $\beta$-carotene have shown both protective and negative effects therefore, a large number of trials are necessary with critical evaluation of scientific data and their mechanism of actions.

\section{REFERENCES}

[1] Arts I, Hollman P. Polyphenols and disease risk in epidemiologic studies. Am J Clin Nutr 2005; 81: 317S-25S.

[2] Choe E, Min DB. Chemistry and reactions of reactive oxygen species in foods. Crit Rev Food Sci Nutr 2006; 46: 1-22.

[3] Marnett LJ. Oxyradicals and DNA damage. Carcinogenesis 2000; 21: 361-70.

[4] Bandyopadhyay U, Das D, Banerjee RK. Reactive oxygen species: Oxidative damage and pathogenesis. Curr Sci 1999; 77: 658-66.

[5] Willcox JK, Ash SL, Catignani GL. Antioxidants and prevention of chronic diseases. Crit Rev Food Sci Nutr 2004; 44: 275-95.

[6] Triantis T, Stelakis A, Demotikali D, Papadopoulos K. Investigation on the antioxidant activity of fruit and vegetable aqueous extracts on superoxide radical anion using chemiluminescence techniques. Anal Chim Acta 2005; 536: 101-5.

[7] Olinski R, Gackowski D, Foksinski M, Rozalski R, Roszkowski K, Jaruga P. Oxidative DNA damage: Assessment of the role in carcinogenesis, atherosclerosis and acquired immunodeficiency syndrome. Free Radic Bio Med 2002; 33: 192-200.

[8] Tiwari AK. Imbalance in antioxidant defense and human diseases: Multiple approach of natural antioxidants therapy. Curr Sci 2001; 81: 1179-87.

[9] Kris-etherton P, Hecker K, Bonanome A, Coval S, Binkoski A, Hilpert K. Bioactive compounds in foods: their role in the prevention of cardiovascular disease and cancer. Am J Med 2002; 113: $71 \mathrm{~S}-8 \mathrm{~S}$.

[10] Halliwell B, Whiteman M. Measuring reactive species and oxidative damage in vivo and in cell culture: How should you do it and what do the results mean? Br J Pharmacol 2004; 142: 231-55.

[11] Scalbert A, Manach C, Morand C, Remesy C. Dietary polyphenols and the prevention of diseases. Crit Rev Food Sci Nutr 2005; 45: 287-306.

[12] Scalbert A, Williamson G. Dietary intake and bioavailability of polyphenols. J Nutr 2000; 130: 2073S-85S.

[13] Cieślik E, Greda A, Adamus W. Contents of polyphenols in fruits and vegetables. Food Chem 2006; 94: 135-42.

[14] Escarpa A, Gonzalez MC. An overview of analytical chemistry of phenolic compounds in foods. Crit Rev Anal Chem 2001; 31: 57139.

[15] Kondratyuk TP, Pezzuto JM. Natural product polyphenols of relevance to Human Health. Pharm Biol 2004; 42: 46-63.

[16] Nichenametla SN, Taruscio TG, Barney DL, Exon JH. A review of the effects and mechanism of polyphenolics in cancer. Crit Rev Food Sci Nutr 2006; 46: 161-83.

[17] Kaur C, George B, Deepa N, Singh B, Kapoor HC. Antioxidant status of fresh and processed tomato-A review. J Food Sci Technol 2004; 41: 479-86.

[18] Rietjens IMCM Boersma MG, Haan L de, et al. The pro-oxidant chemistry of the natural antioxidants vitamin $\mathrm{C}$, vitamin $\mathrm{E}$, carotenoids and flavonoids. Environ Toxicol Pharmacol 2002; 11: 32133.
[19] Larson RA (Eds). Naturally occurring antioxidants. Lewis Publishers, New York, 1997; pp. 83-186.

[20] Prakash D, Dhakarey R, Mishra A. Carotenoids: The phytochemicals of nutraceutical importance. Indian J Agric Biochem 2004; 17: $1-8$.

[21] George B, Kaur C, Khurdiya, DS, Kapoor HC. Antioxidants in tomato (Lycopersium esculentum) as a function of genotype. Food Chem 2004; 84: 45-51.

[22] Stahl W. Bioactivity and protective effects of natural carotenoids. Biochim Biophy Acta 2005; 1740: 101-7.

[23] Ortuńo A, Báidez A, Gómez P, et al. Citrus paradisi and Citrus sinensis flavonoids: Their influence in the defence mechanism against Penicillium digitatum. Food Chem 2006; 98: 351-8.

[24] Sun DC, Chen KS, Chen Y, Chen Q. Content and antioxidant capacity of limonin and nomilin in different tissues of citrus fruit of four cultivars during fruit growth and maturation. Food Chem 2005; 93: 599-605.

[25] Snodderly DM. Evidence for protection against age-related macular degeneration by carotenoids and antioxidant vitamins. Am J Clin Nutr 1995; 62: 1448S-61S.

[26] Block G, Patterson B, Subar A. Fruit, vegetable and cancer prevention: a review of the epidemiological evidence. Nutr Cancer 1992; 18: 1-29.

[27] Gillman MW, Cupples LA, Gagnou D, et al. Protective effect of fruits and vegetables on development of stroke in men. J Am Med Assoc 1995; 273: 1113-17.

[28] Williams JK, Anthony MS, Clarkson TB. Coronary heart disease in rhesus monkeys with diet-induced coronary artery atherosclerosis. Arch Pathol Lab Med 1991; 115: 784-90.

[29] Kohlmeier L, Hastings SB. Epidemiologic evidence of a role of carotenoids in cardiovascular disease prevention. Am J Clin Nutr 1995; 62: 1370-6.

[30] Fawzi WW, Herrera MG, Willet WC, et al. Vitamin A supplementation and dietary vitamin $\mathrm{A}$ in relation to the risk of xerophthalmia. Am J Clin Nutr 1993; 58: 385-91.

[31] Giovannucci E. Tomatoes, tomato-based products, lycopene and cancer: Review of the epidemiologic literature. J Natl Cancer Inst 1995; 87: 1767-76.

[32] Sies H (eds). Antioxidants in Disease Mechanisms and Therapy, Advances in Pharmacology Series, Academic Press, London, 1996; Vol. 38.

[33] Albanes D, Heinonen OP, Taylor PR, et al. $\alpha$-Tocopherol and $\beta$-carotene supplements and lung cancer incidence in the $\alpha$-tocopherol, $\beta$-carotene cancer prevention study: Effects of baseline characteristics and study compliance. J Nat Cancer Inst 1996; 88: $1560-70$.

[34] Cohen LA. A review of animal model studies of tomato carotenoids, lycopene, and cancer chemoprevention. Exp Biol Med 2002; 227: 864-8.

[35] Halliwell B. Antioxidants in human health and disease, Annu Rev Nutr 1996; 16: 33-50.

[36] Clinton SK. Lycopene: Chemistry, biology and implications for human health and disease. Nutr Rev 1998; 56: 35-51.

[37] Rao AV, Agarwal S. Role of lycopene as antioxidant carotenoid in the prevention of chronic diseases: A review. Nutr Res 1999; 19: 305-23.

[38] Kristal AR, Cohen JH. Invited commentary: Tomatoes, lycopene, and prostate cancer. How strong is the evidence? Am J Epidemiol 2000; 151: 124-7.

[39] Giovannucci E. Intake of carotenoids and risk of lung cancer in 2 prospective US cohorts. Am J Clin Nutr 2000; 72: 990-7.

[40] Casso D, White E, Patterson RE, Agurs-Collin T, Kooperberg C, Haines PS. Correlates of serum lycopene in older women. Nutr Cancer 2000; 36: 163-9.

[41] Cohen LA, Zhao Z, Pittman B, Khachik F. Effect of dietary lycopene on $\mathrm{N}$-methylnitrosourea-induced mammary tumorigenesis. Nutr Cancer 1999; 34: 153-9.

[42] Narisawa T, Fukaura Y, Terada K, et al. Prevention of $\mathrm{N}$ methylnitrosourea-induced colon carcinogenesis in F-344 rats by lycopene and tomato juice rich in lycopene. Jpn J Cancer Res 1998; 89: 1003-8.

[43] Wargovich MJ, Jimenez A, Mckee K, et al. Efficacy of potential chemopreventive agents on rat colon aberrant crypt formation and progression. Carcinogenesis 2000; 21: 1149-55. 
[44] Astorg P, Gradelet S, Berges R, Suschetet M. Dietary lycopene decreases the initiation of liver preneoplastic by diethylnitrosamine in the rat. Nutr Cancer 1997; 29: 60-8.

[45] Nagasawa H, Mitamura T, Sakamoto S, Yamamoto K. Effects of lycopene on spontaneous mammary tumour development in SHN virgin mice. Anticancer Res 1995; 15: 1173-8.

[46] Sharoni Y, Giron E, Rise M, Levy J. Effects of lycopene-enriched tomato oleoresin on 7, 12-dimethylbenz[a]anthracene-induced rat mammary tumors. Cancer Detect Prev 1997; 21: 118-23.

[47] Cohen LA. A Review of animal model studies of tomato carotenoids, lycopene, and cancer chemoprevention. Exp Biol Med 1999; 227: 864-8.

[48] Howe GR, Hirohata T, Hislop TG, et al. Dietary factors and risk of breast cancer: Combined analysis of 12 case-control studies. J Natl Cancer Inst 1990; 82: 561-9.

[49] Kushi LHRM, Sellers TA, Zheng W, Folsom AR. Intake of vitamins $\mathrm{A}, \mathrm{C}$ and $\mathrm{E}$ and postmenopausal breast cancer. The Iowa Women's Health Study. Am J Epidemiol 1996; 144:165-74.

[50] Papas AM (eds). Antioxidants status, diet, nutrition and health. CRC Press, Boca Raton, London, New York, Washington, D. C. 1999; pp. 189-210.

[51] Kornsteiner M, Wagner KH, Elmadfa I. Tocopherols and total phenolics in 10 different nut types. Food Chem 2006; 98: 381-7.

[52] Park EJ, Pezzuto JM (eds). Encyclopedia of pharmaceutical Technology. $2^{\text {nd }}$ ed., Marcel Decker, New York. 2002; pp. 97-113.

[53] Packer L, Weber SU (eds). The role of vitamin E in the emerging field of nutraceuticals. Marcel Dekker, New York. 2001; pp. 27-43.

[54] Bast A, Haenen GRMM. The toxicity of antioxidants and their metabolites. Environ Toxicol Pharmacol 2002; 11: 251-8.

[55] Kim DO, Lee CY. Comprehensive study on vitamin C equivalent antioxidant capacity (VCEAC) of various polyphenolics in scavenging a free radical and its structural relationship. Crit Rev Food Sci Nutr 2004; 44: 253-73.

[56] Lee SH, Oe T, Bliar IA. Vitamin C induced decomposition of lipid hydroperoxides to endogenous genotoxins. Science 2001; 292: 2083-6.

[57] Huang J, Agus, DB, Winfree CJ, et al. Dehydroascorbic acid, a blood brain barrier transportable form of vitamin $\mathrm{C}$, mediates potent cerebro protection in experimental stroke. Proc Natl Acad Sci USA 2001; 98: 11720-4.

[58] Lutsenko EA, Carcamo JM, Golde DW. Vitamin C prevents DNA mutation induced by oxidative stress. J Biol Chem 2002; 277: 16895-9.

[59] Frei B, Traber M, The new US dietary reference for vitamins $\mathrm{C}$ and E. Redox Rep 2001; 6: 5-9.

[60] Kumpulainen, JT, Salonen JT (Eds.). Natural antioxidants and food quality in atherosclerosis and cancer prevention, Royal Society of Chemistry, London, 1996.

[61] Kramer K, Packer LR (Eds). $\alpha$-lipoic acid. Marcel Dekker, New York, 2001; 129-64.

[62] Izzo FN, Quartacci MF, Sgherri C. Lipoic acid: a unique antioxidant in the detoxification of activated oxygen species. Plant Physiol Biochem 2002; 40: 463-70.

[63] Hakkinen SH, Karenlampi SO, Mykkanen HM, Heinonen IM, Torronen AR. Ellagic acid content in berries: Influence of domestic processing and storage. Eur Food Res Technol 2000; 212: 75-80.

[64] Proestos C, Boziaris IS, Nychas GJE, Komaitis M. Analysis of flavonoids and phenolic acids in Greek aromatic plants: Investigation of their antioxidant capacity and antimicrobial activity. Food Chem 2006; 95: 664-71.

[65] Amić D, Davidović-amić D, Bešlo D, Trinajstić N. Structureradical scavenging activity relationships of flavonoids. Croat Chem Acta 2003; 76: 55-61.

[66] Hashim MS, Lincy S, Remya V, Teena M, Anila L. Effect of polyphenolic compounds from Coriandrum sativum on $\mathrm{H}_{2} \mathrm{O}_{2}$ - induced oxidative stress in human lymphocytes. Food Chem 2005; 92: 65360 .

[67] Dijsseelbloem N, Berghe WV, Naeyer AD, Haegeman G. Soy isoflavones phyto-pharmaceuticals in interleukin- 6 affections multipurpose nutraceuticals at the cross road of hormone replacement, anticancer and anti-inflammatory therapy. Biochem Pharmacol 2004; 68: 1171-85.

[68] Gee JM, Johnson IT. Polyphenolic compounds: Interactions with the gut and implications for human health. Curr Med Chem 2001; 8: $1245-55$.
[69] Cai Y, Luo Q, Sun M, Corke H. Antioxidant activity and phenolic compounds of 112 traditional medicinal plants associated with anticancer. Life Sci 2004; 74: 2157-84.

[70] Ferguson RL, Philpott M, Karunasinghe N. Dietary cancer and prevention using antimutagens. Toxicology 2004; 198: 147-59.

[71] Andjelković M, Van Camp J, De Meulenaer B, et al. Iron-chelation properties of phenolic acids bearing catechol and galloyl groups. Food Chem 2006; 98: 23-31.

[72] Miller NJ, Larrea MBR. Flavonoids and other plant phenols in the diet: Their significance as antioxidants. J Nutr Environ Med 2002; 12: 39-51.

[73] Krishnan R, Maru GB. Isolation and analyses of polymeric polyphenol fractions from black tea. Food Chem 2006; 94: 331-40.

[74] Santos AC, Uyemura SA, Lopes JL, Bazon JN, Mingatto FE, Cutti C. Effects of naturally occurring flavonoids on lipid peroxidation and membrane permeability transition in mitochondria. Free Radic Biol Med 1998; 24: 1455-61.

[75] Marchand L. Cancer preventive effects of flavonoids. Biomed Pharmacother 2002; 56: 296-301.

[76] Johnson TM, Yu ZX, Ferrans VJ, Lowenstein T, Finkel T. Reactive oxygen species are downstream mediators of p53 dependent apotposis. Proc Natl Acad Sci USA 1996; 93: 11848-52.

[77] Rasmussen SE, Breinholt VNM. Non-nutritive bioactive food constituents of plants: Bioavailability of flavonoids. Int J Vitam Nutr Res 2003; 73: 101-11.

[78] Valenzuela A, Lagos C, Schmidt K, Videla LA. Silymarin protection against hepatic lipid peroxidation induced by acute ethanol intoxication in the rat. Biochem Pharmacol 1985; 34: 2209-12.

[79] Kaul C, Kapoor HC. Antioxidants in fruits and vegetables - the melliniums health. Int J Food Sci Technol 2001; 36: 703-25.

[80] Katalinic V, Milos M, Kulisic T, Jukic M. Screening of 70 medicinal plant extracts for antioxidant capacity and total phenols. Food Chem 2006; 94: 550-7.

[81] Prakash D, Singh BN, Upadhyay G. Antioxidant and free radical scavenging activities of phenols from onion (Allium cepa). Food Chem 2007; 102: 1389-93.

[82] Prakash D, Upadhyay G, Singh BN, Singh HB. Antioxidant and free radical scavenging activities of seeds and agri-waste of some varieties of soybean (Glycine max). Food Chem 2007; 104: 783-90.

[83] Leccese A, Bartolini S, Viti R. Total antioxidant capacity and phenolics content in fresh apricots. Acta Aliment 2008; 37: 65-76.

[84] Bušić V, Kovač S, Gašo-Sokač D, Lepeduš H. Antioxidative activity of anthocyanins from sour cherries. Acta Aliment 2008; 37: 391-7.

[85] Shi J, Nawaz JP, Mittal G, Kakuda Y, Jiang Y. Extraction of polyphenolics from plant material for functional foods-engineering and technology. Food Rev Int 2005; 21: 136-66.

[86] Bunzel M, Ralph J, Steinhart H. Phenolic compounds as cross-links of plant derived polysaccaharides. Czech J Food Sci 2004; 22: 646.

[87] Aruoma OI, Murcia A, Butler J, Halliwell B. Evaluation of the antioxidant actions of gallic acid and its derivatives. J Food Chem 1993; 41: 1880-5.

[88] Huang J, Paulis TD. Antioxidant effects of dihydrocaffeic acid in human EA. hy926 endothelial cells. J Nutr Biochem 2004; 156: 722-9.

[89] Adom K, Sorrells M, Liu R. Phytochemical profiles and antioxidant activity of wheat varieties. J Agric Food Chem 2003; 51: 7825-34.

[90] Kim KH, Tsao R, Yang R, Cui SW. Phenolic acid profiles and antioxidant activities of wheat bran extracts and effect of hydrolysis conditions. Food Chem 2006; 95: 466-73.

[91] Andrade Jr RG, Dalvi LT, Silva Jr JMC, Lopes GKB, Alonso A, Hermes-lima MH. The antioxidant effect of tannic acid on the in vitro copper-mediated formation of free radicals. Arch Biochem Biophys 2005; 437: 1-9.

[92] Turkmen N, Sari F, Velioglu YS. The effect of cooking methods on total phenolics and antioxidant activity of selected green vegetables. Food Chem 2005; 93: 713-8.

[93] Anagnostopoulou MA, Kefalas P, Papageorgiou VP, Assimopoulou AN, Boskou D. Radical scavenging activity of various extracts and fractions of sweet orange peel (Citrus sinensis). Food Chem 2006; 94: 19-25.

[94] Nakagawa H, Takaishi Y, Tanaka N, Tscuchiya K, Shibata H, Higuti T. Chemical constituents from the peels of Citrus. Sudachi. J Nat Prod 2006; 69: 1177-9. 
[95] Esposito K, Giugliano F, Di Palo C, et al. Effect of a Mediterraneanstyle diet on endothelial dysfunction and markers of vascular inflammation in the metabolic syndrome: a randomized trial. JAMA 2004; 292 : 1440-46.

[96] Singh RB, Rastogi SS, Verma R, Laxmi B, Singh R. An Indian experiment with nutritional modulation in acute myocardial infarction. Am J Cardiol 1992; 69: 879-85.

[97] Singh RB, Rastogi SS, Verma R, et al. Randomized, controlled trial of cardioprotective diet in patients with acute myocardial infarction: results of one year follow up. Br Med J 1992; 304: 10159.

[98] Singh RB, Niaz MA, Sharma JP, Kumar R, Rastogi V, Moshiri M. Randomized, double blind, placebo controlled trial of fish oil and mustard oil in patients with suspected acute myocardial infarction: the Indian Experiment of Infarct Survival-4. Cardiovasc Durgs Ther 1997; 11: 485-91.

[99] Singh RB, Pella D, DeMeester F. What to eat and chew in acute myocardial infarction. Eur Heart J 2006; 27: 1628-29.

[100] Singh RB, Rastogi SS, Niaz MA, Ghosh S, Singh R, Gupta S. Effects of fat-modified and fruits and vegetable enriched diets on blood lipids in the Indian diet heart study. Am J Cardiol 1992, 70: 869-74.

[101] Singh RB, Niaz MA, Agarwal P, Beegum R, Rastogi SS. Effect of antioxitant rich foods on plasma ascorbic acid, cardiac enzyme and lipid peroxide levels in patients hospitalized with acute myocardial infarction J Am Diet Assoc 1995; 95: 775-80.

[102] Singh RB, Rastogi SS, Ghosh S, Singh R, Niaz MA. Effects of guava intake on serum total and high density lipoprotein cholesterol levels and on systemic blood pressure. Am J Cardiol 1992; 70: 1287-91.

[103] Singh RB, Sharma VK, Gupta RK. Nutritional modulators of lipoprotein metabolism in patients with risk factors for coronary heart disease. J Am Coll Nutr 1992; 11: 391-8.

[104] Singh RB, Rastogi SS, Ghosh S, Niaz MA, Singh NK: The diet and moderate exercise trial (DAMET): Results after 24 weeks. Acta Cardiol 1992; 47: 543-57.

[105] Maxwell SRJ. Can antioxidants prevent ischaemic heart disease? J Clin Pharm Ther 2008, 18: 85-95.

[106] Lonn EM, Yusuf S. Is there a role for antioxidant vitamins in the prevention of cardiovascular diseases: an update on epidemiological and clinical trials data. Can J Cardiol 1997; 13: 957-65.

(C) Prakash and Gupta; Licensee Bentham Open.

This is an open access article licensed under the terms of the Creative Commons Attribution Non-Commercial License (http://creativecommons.org/licenses/by$\mathrm{nc} / 3.0 /$ ) which permits unrestricted, non-commercial use, distribution and reproduction in any medium, provided the work is properly cited. 